\title{
Changes in serum lipid profile in postmenopausal women with reference to Body mass index (BMI)
}

\author{
Tiwari $\mathbf{J}^{1}$, Naagar JK ${ }^{2}$ \\ ${ }^{1}$ Dr Jyoti Tiwari, Assistant Professor, Deptt.of Medicine, Bundelkand Medical College, Sagar, MP, ${ }^{2}$ Dr Jagrati Kiran \\ Naagar, Assistant Professor, Deptt.of Obstetrics and Gynaecology, Bundelkhand Medical College, Sagar, MP, India
}

Address for Correspondence: Dr. Jyoti Tiwari, Email: drtiwari@ rediffmail.com.

\begin{abstract}
Background and Objective: Menopause is a natural process in the ageing of a women \& it denotes the end of reproductive capacity which menifests as cessation of cyclic ovarian function and cyclic menstruation. The various hormonal changes associated with menopause on the serum lipids play an important role in most cardiac problems in this period. As Life expectancy is increasing in terms of age in women and menopause remains relatively unchanged, now women are spending more of their life span in the post-menopausal period.The aim of our study was to evaluate risk factors for coronary artery disease in post menopausal women. This includes study and comparison of the serum lipid profile in premenopausal and postmenopausal women with reference to body mass index. Material and Method: The study was conducted with 100 premenopausal and 100 post menopausal women. The BMI of 50 women in either group was 18.9-24.9 and another 50 women was 25-29.9. Various factors which may alter lipid profile were excluded. After overnight fast of $12 \mathrm{hrs}, 5 \mathrm{ml}$ venous blood was withdrawn and sent for lipid profile analysis. Results: We observed that there is significantly high serum levels of total cholesterol,LDL,VLDL and triglycerides and significantly low levels of serum HDL in postmenopausal women group in comparison to their pre menopausal counterparts irrespective of their BMI levels $(\mathrm{p}=<0.05)$. Conclusions: Changes in lipid profile in post menopausal women increases the risk of cardio vascular diseases.
\end{abstract}

Key words: Body Mass Index, CAD, Lipid profile, Menopause,

\section{Introduction}

Menopause denotes a condition of permanent cessation of menstruation at the end of reproductive life due to loss of ovarian follicular activity and cessation of menstruation There are various hormonal changes which take place in women after menopause and lead to alterations in lipid metabolism and increase the risk of coronary artery disease in women [1]. Up to the age of 50 yrs incidence of CAD is lower in women but after that the incidence becomes similar in both men and women [2]. As Life expectancy is increasing in terms of age in women and menopause remains relatively unchanged, so women are now spending more of their life in the post-menopause period. Sixty million women in India are above the age of 55 years [3]. It is therefore important to know all menopause related diseases of the women so necessary action can be taken for their healthy life after menopause.

Manuscript received: $11^{\text {th }}$ Apr 2015

Reviewed: $14^{\text {th }}$ Apr 2015

Author Corrected: $4^{\text {th }}$ May 2015

Accepted for Publication: $26^{\text {th }}$ May 2015
Increase in the incidence of cardiovascular disease is related to many risk factors such as Hypertension, Diabetes mellitus, Dyslipedemia, increase in body weight, ageing process, physical inactivity, mental stress, smoking and alcohol intake [4]. In the United States, more than 500,000 women die of cardiovascular disease and about half are due to coronary artery disease (CAD). As the incidence of CAD is higher in men but it increases significantly in women after menopause [5]. The changes in the hormonal status after menopause such as low estrogen, increased luteinizing hormone and follicular stimulating hormone exert significant effect on plasma lipids and lipoproteins metabolism in post menopausal women. In the present study we tried to correlate some of the risk factors as altered lipid profile is associated with increased risk of CAD caused by hormonal changes taking place during menopause. We measured the serum lipid levels in post menopausal women and compared these results with women of reproductive age group with reference to 
body mass index in both the groups. Hypercholesterolemia is a key factor in the pathophysiology of atherosclerosis.

\section{Material and Methods}

This is a cross sectional observational study. The study was conducted in the Department of Medicine Bundelkhand Medial College and associated hospital Sagar, MP during the period of March 2013 to March 2014. After taking written consent from all the patients and permission from the ethical committee, we have selected 100 patients each in the premenopausal and post menopausal group. Age group for premenopausal women was 21 to 35 years and post menopausal was 45-55 yrs of age. The subjects having risk factors which may have an effect on lipid profile like diabetes mellitus, hypertension ( BP > 140/90), chronic kidney disease, chronic liver disease, smoking, dyslipedemia, alcoholism, tobacco chewing, nephrotic syndrome , hypothyroidism and patients on drugs like estrogen, progesterone, beta blockers, steroids,statins and a positive family history of CAD were excluded from the study.

After taking written consent, all the patients were taken for detailed history and medical examination. Proper history of each subject is reported including name, age, sex, address, socioeconomic status, marital status, dietary habbits, present history, past history, family history obstetric history and menstrual history.

Collection of blood sample: Blood sample for serum lipid estimation has to be taken on empty stomach after
$10-12$ hours of fasting. So all the pateients were instructed to take non fatty meal upto $10 \mathrm{PM}$ and then do 10- 12 hours of fasting overnight. Sample has to be collected at 8 AM next day morning. $5 \mathrm{ml}$ of venous blood was withdrawn from anticubital vein with full aseptic precautions. Clear unhaemolysed serum was obtained by centrifugation. Estimation of serum lipids was done with end point colourimetry. Results were obtained in $\mathrm{mg} / \mathrm{dl}$ and converted into $\mathrm{mmol} / \mathrm{L}$ by using appropriate conversion factor since $\mathrm{mmol} / \mathrm{L}$ is $\mathrm{SI}$ (Standard International) unit.

Laboratory investigations: Estimation of following parameters was done by the serum collected. Total cholesterol (TC), Triglyceride (TG), high density lipoprotein cholesterol (HDL-C) and low density lipoprotein cholesterol (LDL-C), very low density lipoprotein (VLDL).

BMI is also known as Quetelet's index [6]. It was calculated by following formula. The Anthopometric measurements were done. Height was measured in Meter and weight was taken in Kgs. By these data BMI was calculated.

$$
\begin{gathered}
\text { Weight }(\mathrm{Kgs}) \\
\text { Height }(\mathrm{M}) 2
\end{gathered}
$$

All the values obtained above were arranged in a table form and master chart was prepared and statistical analysis was done by SPSS software by using student's t test.

\section{Results}

The study was carried out in 100 premopausal and 100 post menopausal women. The results of the study are as follows. General and systemic examination of all the women in both the study groups was normal. Premenopausal women age ranges from 21 to 35 with a mean age of 30.38 and postmenopausal women age ranges from 45 to 55 years with mean age of 44.25 years.

Table 1: Physical parameters of the patients in the study group

\begin{tabular}{|l|l|l|l|l|l|l|}
\hline Parameter & \multicolumn{3}{|l|}{ Premenopausal women $($ Mean \pm SD $)$} & \multicolumn{3}{l|}{ Post menopausal women(Mean \pm SD ) } \\
\hline & $\begin{array}{l}\text { Normal weight } \\
\text { n=50 } \\
\text { BMI 18.9-24-9 }\end{array}$ & $\begin{array}{l}\text { Overweight } \\
\text { n=50 } \\
\text { BMI 25-29.9 }\end{array}$ & P value & $\begin{array}{l}\text { Normal } \\
\text { weight } \mathrm{n}=50 \\
\text { BMI 18.9- } \\
24.9\end{array}$ & $\begin{array}{l}\text { Overweight } \\
\text { N=50 } \\
\text { BMI 25-29.9. }\end{array}$ & Palue \\
\hline Height & $152.68 \pm 6.86$ & $156.45 \pm 6.92$ & $\mathrm{p}>0.05^{* *}$ & $152.22 \pm 5.56$ & $152.14 \pm 5.80$ & $\mathrm{p}>0.05^{* *}$ \\
\hline Weight & $51.25 \pm 8.32$ & $66.22 \pm 5.54$ & $\mathrm{p}<0.05^{*}$ & $51.79 \pm 5.42$ & $68.72 \pm 6.92$ & $\mathrm{p}<0.05^{*}$ \\
\hline BMI & $21.43 \pm 2.22$ & $28.13 \pm 6.76$ & $\mathrm{p}<0.05^{*}$ & $22.68 \pm 2.89$ & $28.92 \pm 3.78$ & $\mathrm{p}<0.05^{*}$ \\
\hline
\end{tabular}

$* \mathrm{p}<0.05$ statistically significant, $\mathrm{p}>0.05 * *$ statistically not significant, $\mathrm{SD}=$ standard deviation 
These are the various observations we found out in our study. In Table -1 we have depicted the physical characterstics in terms of body weight (Kgs), height (Cms) and BMI of both the groups of pre as well as post menopausal women. We have observed that there is a statistically significant difference in weight as well as BMI of normal and overweight group $(\mathrm{p}<0.05)$.

Table 2: Comparison of lipid profile in pre and post menopausal women of normal weight group

\begin{tabular}{|l|l|l|l|}
\hline Parameter & $\begin{array}{l}\text { Premenopausal women } \\
\text { BMI 18.9-24.9 }\end{array}$ & $\begin{array}{l}\text { Postmenopausal women } \\
\text { BMI 18.9-24.9 }\end{array}$ & P value \\
\hline TC (Total cholesterol ) & $176 \pm 30.12$ & $250.12 \pm 28.12$ & $\mathrm{p}<0.05^{*}$ \\
\hline TG (Serum Triglycerides) & $128 \pm 20.14$ & $136.34 \pm 16,36$ & $\mathrm{p}<0.05^{*}$ \\
\hline HDL-C & $64.34 \pm 8.80$ & $46.42 \pm 4.47$ & $\mathrm{p}<0.001^{* *}$ \\
\hline LDL-C & $136.34 \pm 28.92$ & $230.22 \pm 29.85$ & $\mathrm{p}<0.001^{* *}$ \\
\hline VLDL & $26.45 \pm 4,55$ & $28.12 \pm 3.68$ & $\mathrm{p}>0.05^{* * *}$ \\
\hline
\end{tabular}

${ }^{*} \mathrm{p}<0.05$ is stastically significant, $* * \mathrm{p}<0.001$ statistically very significant, $* * * p>0.05$ statistically not very significant. $\mathrm{BMI}=$ Body mass index, HDL-C $=$ High density lipoprotein, LDL-C=Low density lipoprotein, VLDL=Very low density lipoprotein,TC- Total cholesterol,TG=Triglycerides.

In Table -2 we did the comparative study of various lipid fractions in pre menopausal and post menopausal women of normal body weight. The levels of serum total cholesterol (TC) and serum triglycerides (TG)were significantly higher in post menopausal women as compared to pre menopausal women of same BMI $(\mathrm{P}<0.05)$. In this study group HDL Cholestrol is significantly lower in post menopausal women as compared to premenopausal women (p<0.001). LDL Cholestrol was also significantly higher in post menopausal group as compared to pre menopausal group ( $\mathrm{p}<0.001)$. VLDL levels were slightly higher in postmenopausal group $(\mathrm{P}>0.05)$.

Table 3: Comparison of lipid profile parameters in pre and post menopausal women of overweight group

\begin{tabular}{|l|l|l|l|}
\hline Parameter & $\begin{array}{l}\text { Premenopausal women } \\
\text { BMI 25-29.9 }\end{array}$ & $\begin{array}{l}\text { Postmenopausal women } \\
\text { BMI 25-29.9 }\end{array}$ & $\mathrm{p}$ value \\
\hline TC (Total cholesterol ) & $201.12 \pm 24.14$ & $270.24 \pm 24,56$ & $\mathrm{P}<0.001^{* *}$ \\
\hline TG (Serum Triglycerides) & $136.32 \pm 23.21$ & $170.34 \pm 21.45$ & $\mathrm{p}<0.001^{* *}$ \\
\hline HDL-C & $46.23 \pm 7.68$ & $34.46 \pm 8.68$ & $\mathrm{p}<0.001^{* *}$ \\
\hline LDL-C & $192.24 \pm 22.46$ & $256.14 \pm 28.90$ & $\mathrm{p}<0.001^{* *}$ \\
\hline VLDL & $28.24 \pm 2.78$ & $30.60 \pm 5,54$ & $\mathrm{p}>0.05^{* * *}$ \\
\hline
\end{tabular}

$* \mathrm{p}<0.05$ statistically significant, $* * \mathrm{p}<0.001$ statistically very significant, $* * * p>0.05$ statically not very significant. $\mathrm{BMI}=$ Body mass index, HDL-C $=$ High density lipoprotein, LDL-C=Low density lipoprotein, VLDL=Very low density lipoprotein, TC- Total cholesterol, TG=Triglycerides.

In Table- 3 we did a comparison of lipid fractions between premenopausal and post menopausal women of overweight group with high BMI ( 25-29.9), and this revealed that there is significantly higher levels of Total cholesterol, LDL, and triglycerides in post menopausal group $(\mathrm{p}<0.001)$. HDL was significantly lower in the postmenopausal category $(\mathrm{p}<0.001)$. Similar changes were also found by Bade et al [3].

\section{Discussion}

Cardiovascular disease is a leading cause of mortality in both men and women in industrialized world. The various physiological risk factors for cardiovascular disease are complex and the incidence of cardiovascular disease increases with age in both the sexes, but in women the risk increases markedly after menopause [7]. Menopause is the permanent cessation of menstruation which is retrospectively determined following twelve months of amenorrhoea [8]. The immediate symptoms of menopause are the effects of hormonal changes on various organ systems mainly on cardiovascular system. The average age of menopause is 50.5 yrs, but some women may enter menopause at earlier age.

Studies have shown that women are at less risk of developing CAD than their male counterparts, but this benefit is abolished after 60 years of age. After menopause, as there is loss of ovarian functions and depletion of various ovarian hormones. These results in 
adverse changes in glucose and insulin metabolism, body fat distribution, coagulation, fibrinolysis and vascular endothelial dysfunction. We would like to demonstrate various hormonal changes which takes place during menopause. The major effect of Estrogen on lipid metabolism is by its action on regulation of various LDL receptors in Liver. Estrogen acts on these LDL receptors on the hepatocytes and leads to increased clearance of LDL-C particles. By this mechanism levels of LDL-C are regulated in the serum. If the concentration of small dense particles are increased it is characterized by elevated serum total cholesterol , triglycerides, LDL-C,VLDL and reduced HDL-C.In association to these changes in lipid profile the individuals also show increased adipose tissues and increased insulin resistance [9]. These fractions of lipid profile are highly atherogenic and lead to increased chances of CAD.

Estrogen increases HDL-C which is considered to be good cholesterol for CVS by increased hepatic productions of Apolipoprotein -A and decreased hepatic elimination of HDL2 cholestrol by decreasing the activity of hepatic lipase enzyme. Since during menopause estrogen is low and which leads to hampering of all these functions [10].

We have excluded in our study,all the factors which may alter the lipid profile. There is no difference in the results of normal weight as well as overweight postmenopausal women. So we concluded that these changes observed in lipid profile of these postmenopausal women are due to deficiency of hormone estrogen and not related to BMI. Several other studies also have observed similar results $[11,12]$.

Menopause is also associated with decreased physical activity which leads to altered lipid profile. During exercise free fatty acids are required for energy production which is in turn produced by metabolism of triglycerides in the adipose tissues. The trigycerides are hydrolysed to free fatty acids and glycerol by lipoprotein lipase enzyme.Adrenal cortex and gonal hormones are also responsible for degradation of lipids. As gonadal activity is also less in post menopausal perod. All these factors combined together leads to elevated TC,TG,LDL-C, and reduced HDL-C levels in serum of post menopausal women leading to increased risk of CAD. As obesity is also a risk factor for CAD in women. If there is increase in 1 unit of BMI, there is 4$5 \%$ increased risk of CAD.
In our study we have found that there are significant increase in serum total cholesterol TC, LDL-C, Trigycerides in the post menopausal females as compared to premenopausal women $(\mathrm{p}<0.05)$. And there is significantly low level of serum HDL-C in post menopausal women $(p<0.05)$. VLDL cholesterol was also slightly higher in the post menopausal group $(p>0.05)$. In our study we have compared the lipid profile fractions in premenopausal with normal weight and overweight and compared with post menopausal women of normal weight and over weight. As on comparasion we have not found any significant difference in results with reference to body weight. We concluded that these changes in lipid profile in post menopausal group are due to hormonal changes not because of BMI. Our study is in accordance with Bonithon-Kopp who concluded that total cholesterol and LDL cholesterol significantly increased in postmenopausal women [13].

As the role of various drugs like HRT and statins are still controversial, we recommend that there should be a rigorous life style modification in terms of daily exercise routine, low fat diet should be consumed to reduce the levels of TG,LDL-C,TC and to increase the level of HDL-C to reduce the cardio vascular risk ratio and incidences of CAD in post menopausal women.

\section{Conclusion}

As the atherosclerosis is the main culprit for development of CAD. And the lipid profile shows significant increase in total cholesterol, LDL-C, TG as well as slight increase in VLDL-C, along with decreased levels of HDL-C in post menopausal women. We have conducted the study in premenopausal as well as postmenopausal women of normal BMI and overweight. But we could not demonstrate any difference in the results due to weight. So we conclude that these changes found in the lipid profile of postmenopausal women are due to decreased estrogen levels. So postmenopausal women should be counselled regarding life style modification with low fat, high fiber diet and exercise to reduce the incidence of CAD which is the major concern in the present era, As the incidences of CAD are seriously increasing in postmenopausal women these days.

Limitations of the study: In our study the sample size was small. we have included only 200 patients. As well as we have not done Serum estrogen levels in our study as this facitity was not available in our set up , which 
may have shown some changes in the results of our study .

\section{Funding: Nil, Conflict of interest: None \\ Permission of Ethical committee: Yes}

\section{References}

1. Do K A, A Green, J R Guthrie, E C Dudley, H G Burger and L Dennerstein.Longitudinal study of risk factors for coronary heart disease across the menopausal Transition. Am.J. Epidemiol.2000;151(6):584-93.

2. Berg G, Mesch V, Boero L et al.Lipid and lipoprotein profile in menopausal transition. Effects of hormones, age and fat distribution. Horm Metab Res. Apr. 2004 ; 36(4) : 215-20 .

3. Bade G, Shah S,Nahar P, Vaidya S. Effects of menopause on lipid profile in relation to body mass index. Chron young sci 2014;5(1):20-4.

4. Gupta R, Rastogi P, Sarna M, Gupta VP, Sharma SK, Kothari K. Body-mass index, waist- size, waist-hip ratio and cardiovascular risk factors in Urban subejcts. J Assoc Physicians India 2007; 55:621-27.

5. Usoro CA, Adikwuru CC, Usoro IN, Nsonwu AC. Lipid profile of postmenopausal women in Calabar, Nigeria. Pak J Nutr 2006;5:79-82.

6. Park K. Park's Textbook of Preventive and Social Medicine.20th ed. Jabalpur:M/S Banarsidas Bhanot; 2009.

$$
\text { p.345-9. }
$$

7. Domenico d, Marco G, Michele M, Francesco P, Modena AB, Bolis PF et al.The effect of menopause on blood lipid and lipoprotein levels. Atherosclerosis 1999 July; 147:147-53.

8. Hurd WW, Amesse LS, Randolph JF Jr .Menopause.In:Jonathan SB , editor. Novek's Gynaecology , $13^{\text {th }}$ ed.Philadelphia: Lippincott Williams and wilkins;2002.p 1109-42.

9. Tchernof A, Lamarche B, Prud'Homme D, Nadeau A, Moorjani S, Labrie F, et al. The dense LDL Phenotype. Association with plasma lipoprotein levels, visceral obesity, and hyperinsulinemia in men. Diabetes Care 1996;19:629-37.

10. Medina RA, Aranda E, Verdugo C, Kato S, Owen GI. The action of ovarian hormones in cardiovascular disease. Biol Res 2003;36:325-41.

11. Swapnali RK, Kisan R, Murthy DS. Effect of menopause on lipid profile and Apolipoproteins. Al Ameen J Med Sci 2011;4:221-8.

12. Kalavathi L, Dhruvanarayan HR, Zachariah E. Plasma estradiol and lipid profile in perimenopausal women. Indian J Physiol Pharmacol 1991;35:260-2.

13. Bonithon-Kopp C, Scarabin PY, Darne B, Malniejac A, Guize L. Menopause related changes in lipoproteins and some other cardiovascular risk factors. Int J Epidemiol.1990; 19 (1): 42-8.

\section{How to cite this article?}

Tiwari J, Naagar JK. Changes in serum lipid profile in postmenopausal women with reference to Body mass index (BMI). Int J Med Res Rev 2015;3(5):456-460. doi: 10.17511/ijmrr.2015.i5.088. 